\title{
Veterinary acutherapy in management of musculoskeletal disorders: An eye-opener to the developing countries' veterinarians
}

\author{
Olawale Alimi Alimi ${ }^{1,2^{*}}$, Adamu Abdul Abubakar², Abubakar Sadiq Yakubu ${ }^{2}$, Abdullahi Aliyu ${ }^{1}$ and Salman Zubairu \\ Abulkadir ${ }^{1,2}$ \\ ${ }^{1}$ Department of Veterinary Surgery and Radiology, University of Ilorin, Ilorin, Nigeria \\ ${ }^{2}$ Department of Veterinary Surgery and Radiology, Usmanu Danfodiyo University Sokoto, Sokoto, Nigeria
}

\begin{abstract}
Traditional Chinese medicine practitioners believed that the maintenance of the health status of any individual or animal is by the harmonious flow of $C h i$ (life force) along a pathway known as the meridian. Interruption or blockage of Chi brings about disorders, pain, and diseases. Acutherapy, therefore, aims at correcting the interruption or blockage of the harmonious flow of Chi along the meridian to restore the healthy condition of the body system. This correction could be accomplished by either acupuncture or acupressure, and are both collectively referred to as acutherapy. This form of therapy has been used in both humans and animals for several decades. It is, however, just gaining popularity in the treatment of humans and is still not yet in practice among veterinarians for animal patients in most developing countries like Nigeria. This review, therefore, is aimed at exposing veterinarians from the developing countries to the general application of acutherapy with emphasis on the musculoskeletal system and associated pain where it is most applied. It is highly recommended that the universities, where Veterinary Medicine is studied in developing countries, should endeavor to train their veterinary surgeons in this area and see to how acutherapy can be included in the curriculum.
\end{abstract}

Keywords: Acupressure, Acupuncture, Acutherapy, Musculoskeletal, Veterinary.

\section{Introduction}

Acupuncture is a compound system applied to make diagnosis, treat, and prevent diseases using the innate reflex action of the body by skin stimulation at specific points called acupoints with the aid of a needle (Yu et al., 1994; Hulea and Cristina, 2012; Krishan and Narang, 2015; Xie, 2017), used in Traditional Chinese medicine (TCM) practice (Pickett, 2015), while acupressure is carried out by stimulating the acupoints of the body by pressure with the aid of fingers, thumbs, and elbows (Ernst and Lee, 2010; Kim et al., 2012a) to assist in moving Chi or life force (Utzerath, 2014). Other TCM are electroacupuncture (EA), moxibustion, aquapuncture, and gold bead implants. Acutherapy generally aims at strengthening and stimulating the homeostatic mechanisms or machinery of the body (Hulea and Cristina, 2012). It involves influencing precise points (acupoints) that are associated with the internal organs and body (Haltrecht, 1999; Hulea and Cristina, 2012), which are easily recognized and thought to be points of muscle innervation, muscle insertion on bone, and center of muscles, and are generally bilateral (Utzerath, 2014). According to the traditional oriental medicine, for each individual clinical case, there are main (essential) and helper (supporting) points that are combined to enhance the clinical efficacy of acupuncture (Jeong et al., 2013).
Therefore, knowledge of correct acupoints could be beneficial in alleviating pain, increasing cardiac output, suppressing cough reflex, enhancing bone healing, and many other dysfunctions (Hayashi et al., 2007; Goiz-Marquez et al., 2009; Hulea and Cristina, 2012). Adversely, some acupoints may antagonize the clinical effects of others; therefore, good knowledge of acupoint selection is germane (Shiotani et al., 2004; Tsou et al., 2004; Jeong et al., 2013).

Acutherapy is harmless to apply and learn and it can be used as the sole therapy, adjunct therapy, or alternative therapy, when allopathic treatments are insufficient or fails (Yin et al., 2008; Hulea and Cristina, 2012; Utzerath, 2014; Pickett, 2015). As opined by Pickett (2015), Western medicine targets the therapy of extrinsic etiology, like proffering antibiosis, while TCM combats intrinsic problems that compromise the innate self-defense mechanism. It is thus imperative to use acupuncture as an adjunct to conventional therapy (Pickett, 2015).

Some evidences support that acupuncture was primitively used in Northern India and Tibet, but in this modern time, it is believed to have originated from China (Hulea and Cristina, 2012) and has been used for several decades in Eastern Asia to manage a wide range of human and animal diseases where it called by different names, like TCM, Korean medicine, and 
Kampo medicine, depending on the location (Jeong et al., 2013; Xie and Sivula, 2016). In the 1990s, acupuncture was banned in order to promote Western medicine, and not until 1972 articles on surgery with acupuncture anesthesia in conscious patients reached the West (Jeong et al., 2013). Since then, there has been a rise in scientific researches to assess the primordial medical therapy for objective evidence of efficacy (Xie et al., 2001; Xie and Wedemeyer, 2012; Koh et al., 2014; Xie and Sivula, 2016; Magden, 2017). The challenge, however, has been the establishment of a control group (Xie and Sivula, 2016). In the past 30 years, veterinary acupuncture was revived and established, leading to the creation of veterinary acupuncture organizations in many developed countries and consideration of including acupuncture in the veterinary curriculum (Hulea and Cristina, 2012; Jeong et al., 2013). In 1996, the American Veterinary Medical Association assented to acutherapy as an adjunct therapy option for veterinary medical care (Choi et al., 2016), while the National Institutes of Health and the World Health Organization validated acutherapy for human diseases in a scientific report (Magden, 2017; Xie, 2017).

Substitutes to allopathy are sought for many reasons, and pain alleviation seems to be the most common reason (Astin, 1998; Kim et al., 2012b). Qi (Chi) is said to be the energy that regulates body functions and is in continuous circulation through the meridian system in the body, and for the maintenance of health, it is a must that the energy " $q i$ " flows in a smooth and harmonious manner (Hulea and Cristina, 2012; Utzerath, 2014; Snow and Zidonis, 2019). Any disruption in Chi along these meridians brings about disease, pain, and illness (Utzerath, 2014). With a natural peaceful flow of $C h i$ and blood, the body can heal itself. But when there is an obstruction to Chi along the meridian, acupoints are used for restoration (Snow and Zidonis, 2019). Acutherapy is now carried out to unlock "qi" (energy) by using pressure with fingers on acupoints located on the meridians to influence the flow of Chi, blood, and other body fluids (Magden, 2017; Snow and Zidonis, 2019). TCM theories described the manner and role of qi energy and are the backbone in recognizing, locating, and characterizing acupoints of energetic disharmonies in animals (Yu et al., 1994; Hulea and Cristina, 2012). TCM diagnosis precedes treating an animal with acupuncture therapy (Hulea and Cristina, 2012). According to Xie (2017), acupuncture is used in the management of many clinical conditions of animals, especially chronic ones. Acutherapy is frequently used to complement allopathy in aching disorders and is mostly accepted by the owners of animals since it is minimally invasive with low detrimental reaction (Fry et al., 2014; Magden, 2017). From the Chinese medicine perspective, surgical procedures are insults or injuries to the body that invariably disrupt the flow of Chi and blood (Snow and Zidonis, 2019). Postoperatively, acupressure is carried out to alleviate post-operative pain, wash off the effects of anesthesia, reduce scar tissue formation, reduce swelling and body fluids accumulation, and ensure removal of toxins and nourishment of the surgical site by enhancing the circulation of Chi and blood (Snow and Zidonis, 2019). Like in humans, acupuncture is commonly used in neurological dysfunction and orthopedic pains; however, numerous other conditions have been treated successfully with acupuncture (Magden, 2017). It is mostly used in neurological and orthopedic conditions and in internal medicine and oncology cases, as observed in a retrospective work carried out in more than 4,500 patients, predominantly dogs and cats (Shmalberg and Memon, 2015; Magden, 2017). In dogs with musculoskeletal disorders and cervical neurological disorders, the associated impaired ambulation and pain have been reported to be managed with success using acupuncture. In addition, respiration in newborn kittens has been resuscitated, and some immune-mediated conditions and laryngeal hemiplegia in dogs and cats have been managed using acutherapy (Kim and Xie, 2009). Furthermore, significant analgesia (Sheta et al., 2015) and tissue repair and muscle build up have been enhanced in horses (Le Jeune et al., 2016). A variety of disease conditions involving musculoskeletal, nervous, endocrine, and digestive systems have been successfully managed using acupuncture (Choi et al., 2016). Pain and weaknesses resulting from hip dysplasia, intervertebral disk disease (IVDD) and other debilitating musculoskeletal disorders in pets have been managed using acupuncture (Pickett, 2015).

It is usually used for functional problems such as those that have to do with non-infectious inflammation, paralysis, or pain (Krishan and Narang, 2015). In small animal practices, acutherapy is adopted in the management of joint pain, dysplastic hip, granuloma due to licking, asthma in cats, increased gastrointestinal motility, and some disorders with reproduction (Habacher et al., 2006; Krishan and Narang, 2015). Laboratory animals also benefit from acupuncture by clinically improving their conditions and quality of life (Magden, 2017). In large animals, milk fever, nervus facialis palsy, allergy-induced skin irritation, disorders with respiration, non-surgical acute abdominal pain, and a few problems with reproduction have been managed with success using acutherapy (Habacher et al., 2006). The strength of racing animals has been reported to be boosted with acupuncture (Habacher et al., 2006; Krishan and Narang, 2015). Patients undergoing this therapy generally heal, rather than palliative care or just suppressing the clinical signs (Yu et al., 1994; Hulea and Cristina, 2012).

Acupoints are stimulated with various techniques which are dry needle, acupressure, moxibustion, pneumoacupuncture, EA, and aquapuncture (Krishan and Narang, 2015; Xie, 2017). Laser acupuncture has been reported to have great effect in managing aches 
and swelling in certain laboratory investigations (Lorenzini et al., 2010).

There are, however, conditions where acupuncture will not work. For example, in cases of fracture, surgical reduction must be carried out. Nevertheless, acupuncture can be used to reduce post-operative pain, enhance healing, and reduce the possibility of post-operative arthritis in fractures involving the joints (Haltrecht, 1999; Amaro, 2005; Hulea and Cristina, 2012). Also, acupuncture cannot be used as the sole treatment for cancer or malignant tumors, but can, however, be used to reduce the associated pain and boost immunity to aid the fight against the cancerous cells (Hulea and Cristina, 2012). Most of the time, there is none to minimal pain and discomfort when acupuncture treatment is used. It is believed that the pain and discomfort associated with vaccination or hyperthermic needle injection is more than that of the acupuncture treatment (Hulea and Cristina, 2012). Acupuncture is not used in cases of foreign body or infectious viral diseases as confirmed by radiography and enzyme-linked immunoassay (ELISA), respectively (Jeong et al., 2013).

\section{Mechanism of action}

Acutherapy functions similar to a tap which controls the opening or locking of water flow (Hulea and Cristina, 2012). Therefore, patient's energy excesses and/or deficiencies are corrected by stimulating the acupoints in a group of points. The clinical basis of acutherapy is the physiological modification in response to acupoint stimulation (Krishan and Narang, 2015). The physiological changes include, but are not limited to, the secretion of innate opioids, stimulating the body defense system, modulating body temperature, and blood pressure (Krishan and Narang, 2015; Xie, 2017). Internally, major meridians are in connection and communication with definite structures in the body. Any condition or assault to these organs causes interruption in the flowing pattern of Chi. Therefore, organ diseases can be managed by balancing the energy in their respective meridians (Hulea and Cristina, 2012). In pain management, acupuncture analgesia is achieved through stimulation or endorphins release to relieve the pain (Xie, 2017). However, there is no modern research to explain the details of how acupuncture heals (Yu et al., 1994; Tobin et al., 1999; Hulea and Cristina, 2012). In explaining the phenomena behind acupuncture, bioelectric theory has been postulated that acupuncture needles influence the body's bioelectricity in an advantageous manner by helping the system to go back to a state where it can start working normally (Hulea and Cristina, 2012). In addition, humoral theory suggests that acupuncture releases some modulators or substance into the blood and other body fluids. For example, stimulation of certain acupoints releases morphine-like substance (Schoen, 2000; Goiz-Marquez et al., 2009; Cantwell, 2010). Using neural signaling, physiological processes are stimulated upon application of acupuncture needles on the acupoints (Robinson, 2007, 2009). The acupoints are strategic anatomical areas corresponding to neurovascular bundles, blood mesh, and neuromuscular junctions (Robinson, 2009; Magden, 2017). The needles are rotated gently after insertion, which causes disruption in the underneath subcutis layer, creating an automatic impulse to the spinal cord and then to the brain (Langevin and Yandow, 2002; Fox et al., 2014). The spinal cord then receives the somatic sensory information bringing about numerous effects which are dependent on the sites stimulated. While the signal travels through the spinal cord, the dorsal horn is stimulated leading to the release of endogenous opioids, thereby improving analgesia (Zhao, 2008; Kawakita and Okada, 2014; Magden, 2017). The clinical result seen is a response to acupuncture through physiological changes. The influence of acupuncture on internal organs is seen upon stimulation of the bladder meridian bearing the visceral neural pathways and could also be the point where the spinal cord gives off the posterior root of the spinal nerve (Langevin and Yandow, 2002; Robinson, 2007, 2009; Zhao, 2008; Kawakita and Okada, 2014). Circulation and tissue healing enhancement are brought about through increased secretion of peptides that cause vasodilation (Dawidson et al., 1998, 1999; Magden, 2017). Biomechanical responses, like antinociception, antiemetic, and gastrointestinal mobility, occur when the brain cortex receives the nerve impulse (Takahashi, 2011). Hormone regulation has also been reported to be influenced by acupuncture (Magden, 2017; Wei et al., 2017). Functional magnetic resonance imaging and positron emission tomography showed different areas of the brain been stimulated by acupuncture, and this further explains the likely mechanisms of action for acutherapy (Yang et al., 2012; Lu et al., 2014).

Acupuncture has been said to also stimulate the immune system. The works of Haltrecht (1999) and Hulea and Cristina (2012) showed that humoral substances are released after acupuncture treatment. Furthermore, neuro-physiological theory assumes that there is a relationship between acupoints and peripheral nerves (Hulea and Cristina, 2012). This theory is corroborated by the fact that acupoints are usually found at neuromuscular junctions, points of innervation of bone, tendons, and blood vessels (Hulea and Cristina, 2012). In a study involving experimental pain, after acupuncture, there was a rise in the concentration of beta-endorphins which was thought to be the pathway in which acupuncture relieves pain (Xie et al., 2001; Xie and Sivula, 2016). The analgesic effect of acupuncture is thought to be through the secretion of modulators like endorphins inhibiting the conduction of pain stimulus through the central nervous system (Pickett, 2015). Vasodilation with subsequent enhanced blood perfusion of the needled area is thought to aid the process of analgesia. 


\section{General procedure}

There are 14 major meridian systems through which the energy (Chi) flows and which bears the 361 acupoints in the body where meridians are stimulated to either block or release the energy flow through acupressure or acupuncture (Xie and Rimar, 1994; Xie and OrtizUmpierre, 2006). These meridian systems are as shown in Table 1.

Knowledge of the topography of nerve anatomy has been used to locate animal acupoints (Fig. 1), and such translated points have been documented (Lancaster and Bowker, 2012; Robinson, 2012; Magden, 2017). Using acupuncture in animal patients is usually extrapolation of location of acupoints in humans, which are well defined (Table 2) (Yu et al., 1994; Hulea and Cristina, 2012; Magden, 2017). This is easier in nonhuman primates but it becomes challenging in cases of dogs, cats, and horses (Robinson, 2012). Therefore, veterinary acupuncture education is necessary for a detailed understanding of the locations of acupoints and

Table 1. The fourteen meridians and their abbreviations.

\begin{tabular}{|cc|}
\hline Meridian & Abbreviation \\
\hline Lung & LU \\
\hline Heart & HT \\
\hline Pericardium & PC \\
Spleen & SP \\
\hline Kidney & KI \\
\hline Liver & LIV \\
\hline Large Intestine & LI \\
\hline Small Intestine & SI \\
\hline Triple Heater & TH \\
\hline Stomach & ST \\
\hline Bladder & BL \\
\hline Gallbladder & GB \\
\hline Governing Vessels & GV \\
\hline Conception Vessels & CV \\
\hline
\end{tabular}

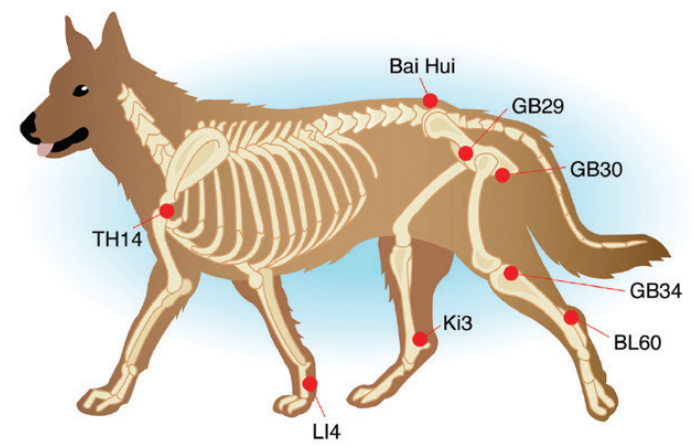

nervous system anatomy. The areas where the pressure is being exerted are called acupoints, which are easily recognized and thought to be neuromuscular junctions, points of muscular insertion, or some muscular midpoints that are always found on either side of paired structures (Utzerath, 2014). Most acupoints are still accessible at about $1.5-3 \mathrm{~mm}$ away from the exact point and are distinct from other parts of the skin with an increased electrical conductivity (Hulea and Cristina, 2012). In acupressure, the pressure is applied on the acupoints with the fatty tip of the thumb by a rotational pattern, mild pulsation, slight oscillating movement, or gentle rubbing (Utzerath, 2014). In the thumb-pressure method, the thumb is held between $45^{\circ}$ and $90^{\circ}$ to the body of the dog, this is to ensure the fingernail does not cause pain to the animal (Utzerath, 2014). The duration of acutherapy varies from 10 seconds to 30 minutes and is applied for a maximum of three times per week for duration of up to 6 weeks, depending on the clinical result (Hulea and Cristina, 2012).

Acupressure is started by easing and holding a direct pressure on an acupoint while the dog is held with the second hand to monitor any reaction (Utzerath, 2014). Reactions, like sighing, farting, extrusion of the tongue, pandiculating, licking the hand of acutherapist, indicate that some of the stagnated energy (Chi) has been moved (Utzerath, 2014). To derive maximum benefit from acutherapy, avoid feeding, rigorous workout, or giving the animal a bath just pre- or post-acutherapy; resting a treated animal is encouraged after acutherapy.

Even though acutherapy is one of the safest forms of treatments when handled by an expert (Haltrecht, 1999; Cho and Kim, 2008; Yin et al., 2008; Hulea and Cristina, 2012), there are some unwanted effects, which include rebound for about 72 hours, followed by improvement, patient showing excess of energy or fatigue for about 48 hours, and accidental needle breakage in the subcutaneous layer or skin (Hulea and Cristina, 2012), and also hematoma, in very rare situations (Hulea and Cristina, 2012). Most of the time, there is no to minimal pain and discomfort when acupuncture treatment is used.

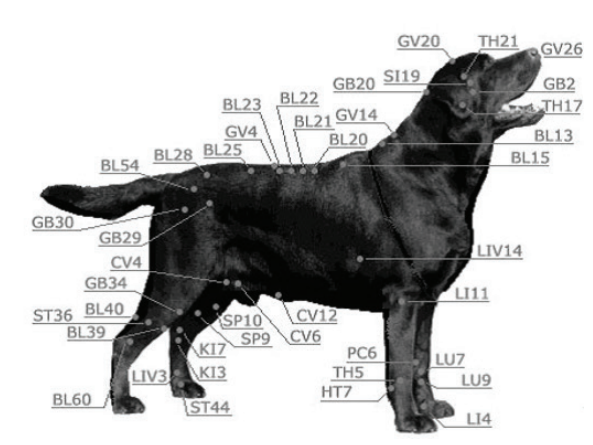

Fig. 1. Some of the acupressure points (Hulea and Cristina, 2012; Utzerath, 2014). 
Table 2. Some selected acupoints, locations, and clinical applications involving musculoskeletal disorders.

\begin{tabular}{|c|c|c|}
\hline Acupoints & Location & Clinical applications \\
\hline LI-1 & $\begin{array}{l}\text { Proximal to the coronary band at the craniomedial aspect of the } \\
\text { hoof of the forelimb }\end{array}$ & $\begin{array}{l}\text { Lameness of the forelimb, laminitis, } \\
\text { navicular disease, pharyngitis, nasal } \\
\text { discharge }\end{array}$ \\
\hline LI-3 & $\begin{array}{l}\text { Over the interosseous muscle on the craniomedial aspect of the } \\
\text { fetlock, distal to the end of the second metacarpal }\end{array}$ & $\begin{array}{l}\text { Toothache, inflammation of tendon, fetlock } \\
\text { pain }\end{array}$ \\
\hline LI-4 & $\begin{array}{l}\text { Between the second and third metacarpal bones at the medial } \\
\text { aspect of the forelimb at about proximal one-third of the } \\
\text { distance between the carpus and fetlock }\end{array}$ & $\begin{array}{l}\text { Immunosuppression, nose bleeding, facial } \\
\text { paralysis, tendinitis, dental disorders, sore } \\
\text { throat }\end{array}$ \\
\hline LI-15 & $\begin{array}{l}\text { Located at the shoulder region on the cranial margin of the } \\
\text { acromial head of the deltoideus, cranial and distal to the } \\
\text { acromion process }\end{array}$ & $\begin{array}{l}\text { IVDD, cervical pain, shoulder pain, and } \\
\text { lameness }\end{array}$ \\
\hline ST-31 & $\begin{array}{l}\text { Caudoventral to the tuber coxae in the depression at its lower } \\
\text { border }\end{array}$ & Arthritis or pain of the stifle, colic \\
\hline ST-34 & Belly of vastus lateralis, proximal and lateral to the patella & $\begin{array}{l}\text { Hind limb paralysis, inflammation of the } \\
\text { stifle }\end{array}$ \\
\hline ST-35 & $\begin{array}{l}\text { The depression lateral and distal to the patellar ligament and } \\
\text { patella, respectively }\end{array}$ & $\begin{array}{l}\text { Ligament disorders, pain, and osteoarthritis } \\
\text { of stifle, paresis of pelvic limb }\end{array}$ \\
\hline ST-41 & $\begin{array}{l}\text { Between the long and lateral digital extensor at the ventral edge } \\
\text { of the lateral malleolus }\end{array}$ & Hind limb paralysis, constipation \\
\hline SP-9 & $\begin{array}{l}\text { The depression about the level of the ligament of patellar in } \\
\text { front of the saphenous vein }\end{array}$ & $\begin{array}{l}\text { Arthritis and pain of the stifle, jaundice, } \\
\text { stranguria }\end{array}$ \\
\hline SP-21 & $\begin{array}{l}\text { About same level of the point of shoulder on the lateral thorax } \\
\text { at seventh intercostal space }\end{array}$ & $\begin{array}{l}\text { Generalized body pain, dyspnea, digestive } \\
\text { disorders, fore and hind limb weakness }\end{array}$ \\
\hline BL-11 & $\begin{array}{l}\text { Few distance away from the dorsal midline at the level of } \\
\text { second thoracic vertebral space }\end{array}$ & $\begin{array}{l}\text { Stiffness of the cervical vertebrae, forelimb } \\
\text { paralysis, arthritis, IVDD }\end{array}$ \\
\hline BL-37 & $\begin{array}{l}\text { At the level of the tuber ischia in the groove between the } \\
\text { semitendinosus and biceps femoris muscles }\end{array}$ & $\begin{array}{l}\text { Lameness of hip, stifle and hock origin, hind } \\
\text { limb paralysis, muscle atrophy }\end{array}$ \\
\hline TH-5 & $\begin{array}{l}\text { In the interosseous space of radius and ulna on the lateral } \\
\text { surface of the fore limb, a bit proximal to the carpus }\end{array}$ & IVDD, fever, otitis, cervical pain \\
\hline TH-9 & $\begin{array}{l}\text { At the terminal of the groove between the lateral ulnaris and the } \\
\text { common digital extensor muscle }\end{array}$ & Paralysis, general analgesia point \\
\hline GB-29 & $\begin{array}{l}\text { In the depression halfway between the greater trochanter of the } \\
\text { femur and iliac wing }\end{array}$ & $\begin{array}{l}\text { Hip dysplasia, coxofemoral joint arthritis, } \\
\text { hind limb paralysis or pain }\end{array}$ \\
\hline GB-30 & $\begin{array}{l}\text { Between the greater trochanter of the femur and ischial } \\
\text { tuberosity in the depression about the mid-way }\end{array}$ & $\begin{array}{l}\text { Coxofemoral osteoarthritis, pain of the } \\
\text { gluteus, hind limb paralysis, or paresis }\end{array}$ \\
\hline LIV-3 & $\begin{array}{l}\text { Proximal one-third of the distance from the tarsus to fetlock on } \\
\text { the craniomedial surface of the third metatarsus }\end{array}$ & Paralysis of hind limb, fetlock pain \\
\hline SI-3 & $\begin{array}{l}\text { On the lateral aspect of the fifth metacarpal proximal to the } \\
\text { metacarpophalangeal joint }\end{array}$ & $\begin{array}{l}\text { Thoracolumbar pain, IVDD, shoulder pain, } \\
\text { pharyngitis }\end{array}$ \\
\hline SI-9 & $\begin{array}{l}\text { The depression at the junction of the lateral and ling heads of } \\
\text { triceps brachii with the deltoidues muscle caudal to the humerus }\end{array}$ & $\begin{array}{l}\text { Paresis or paralysis of the forelimb, } \\
\text { generalized pain }\end{array}$ \\
\hline KID-7 & $\begin{array}{l}\text { On the cranial border of the Achilles tendon at the caudomedial } \\
\text { surface of the hind limb }\end{array}$ & $\begin{array}{l}\text { Varying edema, paralysis, or paresis of the } \\
\text { hind limb }\end{array}$ \\
\hline
\end{tabular}

Adapted from Hulea and Cristina (2012); Xie and Preast (2007).

The acupuncture session is ended by massaging the whole length of the spine on either side for about half a minute, followed by mild rubbing of the body as if dandruff is being brush away, to connect the energies in the body (Utzerath, 2014). The pet is kept calm for a short period thereafter (Utzerath, 2014).

Applications in the musculoskeletal system

Acupuncture has gotten wide acceptance as a noninvasive and less risky therapy for mitigating aches 
and inflammation through stimulation release of neurochemicals and modulators (Han and Terenius, 1982; Zijlstra et al., 2003). In many species of animals, it is, therefore, an alternative therapy to musculoskeletal disorders (Choi, 2009; Crouch, 2009; Koski, 2011) with no radiographic improvement in the condition but marked clinical improvement and success (Choi et al., 2016). Some authors have reported several clinical trials indicating that acupuncture benefitted hip dysplastic dogs in relieving the associated excruciating pain (Jaeger et al., 2006, 2007; Marx et al., 2014). Choi et al. (2016) concluded that acupuncture is an effective medical intervention for degenerative joint diseases (DJD) in captive raptors based on their experience on management of a raptor once weekly for 2 months using selected acupoints on stomach, bladder, and gall bladder meridians. This was adopted after the failure of allopathic therapy. Acupuncture has been reported to alleviate geriatric conditions, which include general body ache, osteoarthritis (Fig. 2), hind end feebleness, and other long-standing diseases that reduce the extent of sound health (Xie, 2017). In sport medicine, exercise-induced or related impairment, like chronic pain, arthritis, and musculoskeletal injuries, could be managed by acupuncture by increasing blood flow to relieve pain and enhance the health of the affected regions (Xie, 2017)

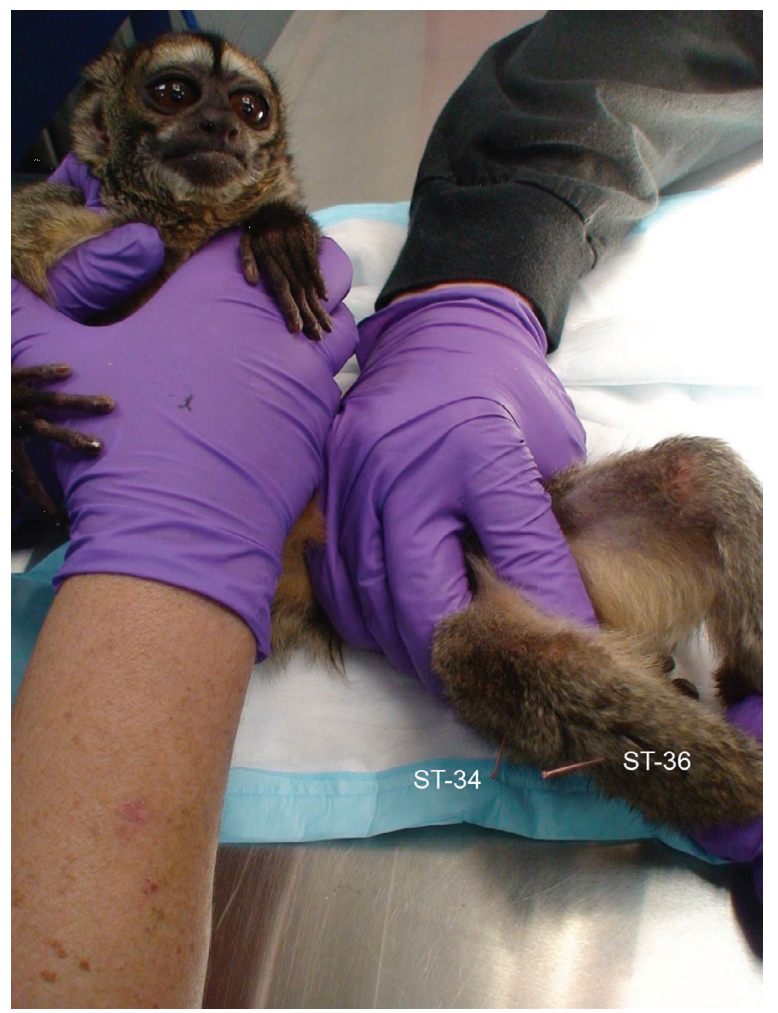

Fig. 2. Acupuncture session for management of knee osteoarthritis in Owl monkey (Aotus spp) using ST-34 and ST-36 (Magden, 2017).
With exercise, dogs can feel aches and pains in the joints and muscle for a day or two (Utzerath, 2014). The pain can as well be chronic as a result of conditions like arthritis or DJD, therefore the need for ongoing painless support (Utzerath, 2014). In both cases, pain and inflammation can be effectively reduced and the range of motion is enhanced with acupressure (Utzerath, 2014).

Acupressure relieves pain and inflammation in muscles and joints by causing the secretion of natural painkillers (Utzerath, 2014). Gold bead or wire implantation and aqua acupuncture (acupoint injection) have been reported to be the most frequently adopted acupuncture techniques in the management of hip dysplasia (Xie and Sivula, 2016). In managing post-surgical pain, plasma concentration of opioid peptide increased significantly in groups that received acupuncture and one-third Zoletil than the groups that received a normal dosage of Zoletil and blank control groups during abdominal surgery, while the plasma concentration was in the reverse of that opioid peptide as reported by Xie and Sivula (2016). Therefore, acupuncture could mitigate post-surgical pain and decrease the dosage of analgesia. Sufficient surgical analgesia has also been reported to be provided by acupuncture in cattle, cats, and dogs (Kim et al., 2004; Xie and Sivula, 2016).

Xie and Sivula (2016) reported a reduced, inspired isoflurane volume with stable cardiopulmonary activities when cats undergoing elective ovariohysterectomy received EA as compared to morphine. From a study involving 69 cats and dogs conducted by Janssens et al. (1979), it was found that acupuncture reversed respiratory depression or apnea under anesthesia to either normal or close to normal values within 10-30 seconds of acutherapy in $100 \%$ of the animals.

Analgesia is seen in acupressure therapy, which is in tandem with acupuncture analgesia theory (Kim et al., 2012a). The pain is said to be reduced by stimulating the pathways of serotonin, noradrenalin, and opioid for other inflammatory conditions that have not been fully established (Kim et al., 2012b). Also, Skarda and Muir (2003) reported an equal analgesic effect of EA and $0.1 \mathrm{ng} / \mathrm{kg}$ intravenous butorphanol on an induced rectal pain.

A more successful clinical outcome was reported when allopathic therapy was combined with acupuncture in the management of IVDD in dogs (Hayashi et al., 2007; Xie and Sivula, 2016). Furthermore, Joaquim et al. (2010) compared surgery and EA in the management of thoracolumbar IVDD in 40 dogs and observed a high success rate $(78.9 \%)$ in dogs that underwent EA alone as compared to those that underwent EA and surgery and surgery alone with $72.7 \%$ and $40 \%$, respectively, for recovery of locomotion and improved neurologic deficits. Furthermore, a clinical success was reported by Goiz-Marquez et al. (2009) using acupuncture in the management of idiopathic epileptic seizures in $15 \mathrm{dogs}$. 


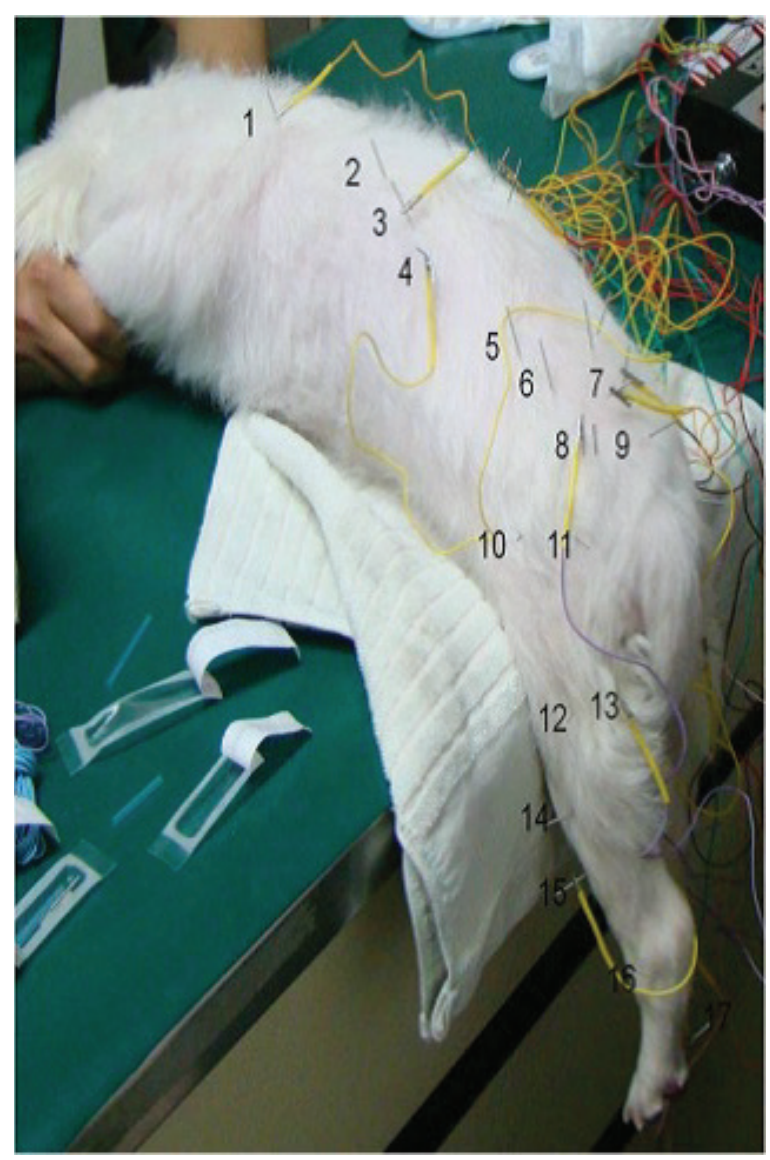

Fig. 3. Pekingese dog undergoing acupuncture for management of IVDD (Kim et al. 2012).

In the management and treatment of pain, acutherapy is complementarily frequently adopted (Ernst and Lee, 2010; Kim et al., 2012a). The use of acupressure in musculoskeletal pain therapy causes less to no side effects than drug treatments or allotherapy (Kim et al., 2012b). Kim et al. (2012b) explored literatures on acupressure effectiveness and reported an improved musculoskeletal pain reduction when compared to usual physical therapy.

Sharifi et al. (2009) reported the enhanced tendon healing and rapid remodeling of collagenous fibers in a study establishing how rapid a full thickness split Achilles tendon can heal with acupuncture therapy. Kim et al. (2012a) reported a Pekingese dog with multiple thoracolumbar IVDD that was managed using EA and oriental herbal medicine with restoration of movement and proprioception of spinal posture of the patient (Fig. 3).

\section{Conclusion and Recommendations}

With the vast benefits of acutherapy and few cautions and contraindications, it is, therefore, highly recommended that veterinary surgeons in developing countries should take a certification course in veterinary acutherapy to enhance their clinical output by having the knowledge of a non-invasive procedure that could serve as either an alternative or a complementary therapy to surgery. In addition to being alternative or complementary to surgical procedures, the knowledge of acutherapy will also assist in enhancing the recovery of surgical patients from the effect of anesthesia and surgical trauma.

It is also highly recommended that the universities where Veterinary Medicine is studied should endeavor to train their veterinary surgeons in this area and see to how acutherapy can be included in the curriculum.

\section{Conflict of interest}

The authors declare that there is no conflict of interest.

\section{References}

Amaro, J. 2005. Acupuncture in veterinary medicine. Retrieved October 13, 2019, Dynamic Chiropractic. Available via: https://www.dynamicchiropractic. $\mathrm{com} / \mathrm{mpacms} / \mathrm{dc} /$ article.php? $\mathrm{id}=50103$

Astin, J.A. 1998. Why patients use alternative medicine: results of a national study. J. Am. Med. Assoc. 279(19), 1548-1553.

Cantwell, S.L. 2010. Traditional Chinese veterinary medicine: the mechanism and management of acupuncture for chronic pain. Top. Companion Anim. Med. 25(1). 53-58.

Cho, S.J. and Kim, O. 2008. Acupuncture treatment for idiopathic Horner's syndrome in a dog. J. Vet. Sci. 9(1), 117-119.

Choi, K.H. 2009. Acupuncture treatment for feline multifocal intervertebral disc disease. J. Feline Med. Surg. 11(8), 706-710.

Choi, K.H., Buhl, G. and Ponder, J. 2016. Raptor acupuncture for treating chronic degenerative joint disease. J. Acupunct. Meridian. Stud. 9(6), 330334.

Crouch, M.A. 2009. Egg binding and hind limb paralysis in an African Penguin - a case report. Acupunct. Med. 27(1), 36-39.

Dawidson, I., Angmar-Månsson, B., Blom, M., Theodorsson, E. and Lundeberg, T. 1999. Sensory stimulation (acupuncture) increases the release of calcitonin gene-related peptide in the saliva of xerostomia sufferers. Neuropeptides 33(3), 244250.

Dawidson, I., Blom, M. and Theodorsson, E. 1998. Sensory stimulation (acupuncture) increases the release of vasoactive intestinal polypeptide in the saliva of xerostomia sufferers. Neuropeptides 32(6), 543-548.

Ernst, E. and Lee, M.S. 2010. Acupressure: an overview of systematic reviews. J. Pain Symptom. Manage. 40(4), e3-e7.

Fox, J.R., Gray, W., Koptiuch, C., Badger, G.J. and Langevin, H.M. 2014. Anisotropic tissue motion induced by acupuncture needling along Intermuscular connective tissue planes. J. Altern. Complement. Med. 20(4), 290-294. 
Fry, L.M., Neary, S.M., Sharrock, J. and Rychel, J.K. 2014. Acupuncture for analgesia in veterinary medicine. Top. Companion Anim. Med. 29(2), 35-42.

Goiz-Marquez, G., Caballero, S., Solis, H., Rodriguez, C. and Sumano, H. 2009. Electroencephalographic evaluation of gold wire implants inserted in acupuncture points in dogs with epileptic seizures. Res. Vet. Sci. 86(1), 152-161.

Habacher, G., Pittler, M.H. and Ernst, E. 2006. Effectiveness of acupuncture in veterinary medicine: systematic review. J. Vet. Intern. Med. 20(3), 480-488.

Haltrecht, H. 1999. Veterinary acupuncture: complementary and alternative veterinary medicine. Can. Vet. J. 40, 401-403.

Han, J.S. and Terenius, L. 1982. Neurochemical basis of acupuncture analgesia. Annu. Rev. Pharmacol. Toxicol. 22(7), 193-220.

Hayashi, A.M., Matera, J.M., Silva, T.S., Carolina, A., Campos, B.D., Pinto, F., Renata, S. and Cortopassi, G. 2007. Electro-acupuncture and Chinese herbs for treatment of cervical intervertebral disk disease in a dog. J. Vet. Sci. 8(1), 95-98.

Hulea, C.I. and Cristina, R.T. 2012. Acupuncture as a therapeutic tool in health disorders in animals : a review. J. Anim. Sci. Biotechnol. 45(2), 166-177.

Jaeger, G.T., Larsen, S., Søli, N. and Moe, L. 2006. Double-blind, placebo-controlled trial of the painrelieving effects of the implantation of gold beads into dogs with hip dysplasia. Vet. Rec. 158(21), $722-726$.

Jaeger, G.T., Larsen, S., Søli, N. and Moe, L. 2007. Two years follow-up study of the pain-relieving effect of gold bead implantation in dogs with hipjoint arthritis. Acta Vet. Scand. 49(1), 1-7.

Janssens, L., Altman, S. and Rogers, P.A.M. 1979. Respiratory and cardiac arrest under general anaesthesia: treatment by acupuncture of the nasal philtrum. Vet. Rec. 105(12), 273-276.

Jeong, J., Song, J., Jo, H., Kim, J., Yoon, S., Park, C., Kim, S., Roh, S., Lee, B.H., Yang, C.H. and Kim, H.Y. 2013. Simple acupoints prescription flow chart based on meridian theory : a retrospective study in 102 dogs. Evid. Based Complement. Alternat. Med. 2013, 1-13.

Joaquim, J.G.F., Luna, S.P.L., Brondani, J.T., Torelli, S.R., Rahal, S.C. and De Freitas, F.P. 2010. Comparison of decompressive surgery, electroacupuncture, and decompressive surgery followed by electroacupuncture for the treatment of dogs with intervertebral disk disease with longstanding severe neurologic deficits. J. Am. Vet. Med. Assoc. 236(11), 1225-1229.

Kawakita, K. and Okada, K. 2014. Acupuncture therapy: mechanism of action, efficacy, and safety: a potential intervention for psychogenic disorders? Bio. Psycho. Social. Med. 8(1), 1-7.
Kim, D.H., Cho, S.H., Song, K.H. and Lee, S.E. 2004. Electroacupuncture analgesia for surgery in cattle. Am. J. Chin. Med. 32(1), 131-140.

Kim, M.S. and Xie, H. 2009. Use of electroacupuncture to treat laryngeal hemiplegia in horses. Vet. Rec. 165(20), 602-603.

Kim, S.H., Kim, N.S., Lee, K.C., Lee, H.B. and Kim, M.S. 2012a. Treatment of multiple thoracolumbar intervertebral disc disease using electroacupuncture and oriental herbal medicine in a dog. Pak. Vet. J. 32(4), 631-634.

Kim, Y.C., Lee, M.S., Park, E., Lew, J. and Lee, B. 2012b. Acupressure for the treatment of musculoskeletal pain conditions: a systematic review. J. Musculoskelet. Pain 20(2), 116-121.

Koh, R.B., Isaza, N., Xie, H., Cooke, K. and Robertson, S.A. 2014. Effects of maropitant, acepromazine, and electroacupuncture on vomiting associated with administration of morphine in dogs. J. Am. Vet. Med. Assoc. 244(7), 820-829.

Koski, M.A. 2011. Acupuncture for zoological companion animals. Vet. Clin. North Am. Exot. Anim. Pract. 14, 141-154.

Krishan, G. and Narang, A. 2015. Integrative therapies in veterinary practice. J. Pharmacol. Pharmacother. 2(1), 50-55.

Lancaster, L.S. and Bowker, R.M. 2012. Acupuncture points of the horse's distal thoracic limb: a neuroanatomic approach to the transposition of traditional points. Animals 2(3), 455-471.

Langevin, H.M. and Yandow, J.A. 2002. Relationship of acupuncture points and meridians to connective tissue planes. Anat. Rec. 269(6), 257-265.

Le Jeune, S., Henneman, K. and May, K. 2016. Acupuncture and equine rehabilitation. Vet. Clin. North Am. Equine Pract. 32(1), 73-85.

Lorenzini, L., Giuliani, A., Giardino, L. and Calzà, L. 2010. Laser acupuncture for acute inflammatory, visceral and neuropathic pain relief: an experimental study in the laboratory rat. Res. Vet. Sci. 88(1), 159-165.

Lu, Y., Huang, Y., Tang, C., Shan, B., Cui, S., Yang, J., Chen, J., Lin, R., Xiao, H., Qu, S. and Lai, X. 2014. Brain areas involved in the acupuncture treatment of AD model rats: a PET study. BMC Complement. Altern. Med. 14(178), 1-8.

Magden, E.R. 2017. Spotlight on acupuncture in laboratory animal medicine. Vet. Med. (Auck1). 8, 53-58.

Marx, C., Silveira, M.D., Selbach, I., Da Silva, A.S., Braga, L.M.G.D.M., Camassola, M. and Nardi, N.B. 2014. Acupoint injection of autologous stromal vascular fraction and allogeneic adipose-derived stem cells to treat hip dysplasia in dogs. Stem Cells Int. 2014, 391274; doi:10.1155/2014/391274

Pickett, L. 2015. Veterinary acupuncture. Retrieved October 20, 2019, from Delaware Golden Available via https://www.dvgrr.org/wp-content/ 
uploads/2015/11/Education_Health_Veterinary_ Acupuncture.pdf

Robinson, N.G. 2007. Veterinary acupuncture: an ancient tradition for modern times. Altern. Complement. Ther. 13(5), 259-265.

Robinson, N.G. 2009. Making sense of the metaphor: wow acupuncture works neurophysiologically. J. Equine Vet. Sci. 29(8), 642-644.

Robinson, N.G. 2012. One medicine, one acupuncture. Animals 2(3), 395-414.

Schoen, A.M. 2000. Equine acupuncture : incorporation into lameness diagnosis and treatment. Am Assoc Equine Pract. 46, 80-83.

Sharifi, D., Sasani, F., Bakhtiari, J. and Rezaei, T. 2009. The effect of acupuncture therapy on the repair of the calcaneal tendon (tendo calcaneus communis) in dogs. Turk. J. Vet. Anim. Sci. 33(3), 181-184.

Sheta, E., Ragab, S., Farghali, H. and El-Sherif, A. 2015. Successful practice of electroacupuncture analgesia in equine surgery. J. Acupunct. Meridian. Stud. 8(1), 30-39.

Shiotani, A., Tatewaki, M., Hoshino, E. and Takahashi, T. 2004. Effects of electroacupuncture on gastric myoelectrical activity in healthy humans. Neurogastroenterol. Motil. 16(3), 293-298.

Shmalberg, J. and Memon, M.A. 2015. A retrospective analysis of 5,195 patient treatment sessions in an integrative veterinary medicine service: patient characteristics, presenting complaints, and therapeutic interventions. Vet. Med. Int. 2015, 983621; doi:10.1155/2015/983621.

Skarda, R.T. and Muir, W.W. 2003. Comparison of electroacupuncture and butorphanol on respiratory and cardiovascular effects and rectal pain threshold after controlled rectal distention in mares. Am. J. Vet. Res. 64(2), 137-144.

Snow, A. and Zidonis, N. 2019. Post-operation acupressure for dysplastic dogs. Retrieved October 20, 2019, Whole Dog Journal. Available via https://www.whole-dog-journal.com/health/postoperation-acupressure-for-dysplastic-dogs/

Takahashi, T. 2011. Mechanism of acupuncture on neuromodulation in the gut-a review. Neuromodulation 14(1), 8-12.

Tobin, T., Harkins, J.D. and Sams, R.A. 1999. Testing for therapeutic medications: analytical/ pharmacological relationships and "Limitations" on the sensitivity of testing for certain agents. J. Vet. Pharmacol. Therap. 22, 220-233.

Tsou, M.T., Huang, C.H. and Chiu, J.H. 2004. Electroacupuncture on PC6 (Neiguan) attenuates ischemia/reperfusion injury in rat hearts. Am. J. Chin. Med. 32(6), 951-965.
Utzerath, B. 2014. 7 acupressure points to put an end to pain. Mansfield, PA: Dogs Naturally Magazine. Available via www.DogsNaturallyMagazine.com

Wei, Y., Dong, M., Zhong, L., Liu, J., Luo, Q., Lv, Y., Mo, S., Sun, J., Liu, F., Xu, F., Yan, C. and Dong, J. 2017. Regulation of hypothalamic-pituitary-adrenal axis activity and immunologic function contributed to the anti-inflammatory effect of acupuncture in the OVA-induced murine asthma model. Neurosci. Lett. 636, 177-183.

Xie, H. 2017. Veterinary acupuncture: indications and contraindications. 1-5. Available via https:// pdfsecret.com/download/veterinary-acupunctureindications-and-contraindications_59faaa20d64ab 28ae25f12a0 pdf\#

Xie, H. and Ortiz-Umpierre, C. 2006. What acupuncture can and cannot treat. J. Am. Anim. Hosp. Assoc. 42(4), 244-248.

Xie, H. and Preast, V. 2007. Xie's veterinary acupuncture. Oxford, UK: Blackwell Publishing.

Xie, H. and Sivula, N. 2016. Review of veterinary acupuncture clinical trials. Am. J. Tradit. Chin. Vet. Med. 11(1), 49-60.

Xie, H. and Wedemeyer, L. 2012. The validity of acupuncture in veterinary medicine. Am. J. Tradit. Chin. Vet. Med. 7(1), 35-43.

Xie, H., Ott, E.A., Harkins, J.D., Tobin, T., Colahan, P.T. and Johnson, M. 2001. Influence of electroacupuncture on pain threshold in horses and its mode of action. J. Equine Vet. Sci. 21(12), 591-600.

Xie,S.H.andRimar,T.1994.Anintroductiontoveterinary acupuncture. Retrieved December 12, 2019. Available via https://pdfs.semanticscholar.org/568a/ dda8c8ab7a89e1d876a33b321a555d7414bc.pdf

Yang, J., Zeng, F., Feng, Y., Fang, L., Qin, W., Liu, X., Song, W., Xie, H., Chen, J. and Liang, F. 2012. A PET-CT study on the specificity of acupoints through acupuncture treatment in migraine patients. BMC Complement. Altern. Med. 12, 1-7.

Yin, C.S., Jeong, H., Park, H., Baik, Y., Yoon, M., Choi, C. and Koh, H.G. 2008. A proposed transpositional acupoint system in a mouse and rat model. Res. Vet. Sci. 84, 159-165.

Yu, C., Zhang, K., Lu, G., Xu, J., Xie, H., Lui, Z., Wang, Y. and Zhu, J. 1994. Characteristics of acupuncture meridians and acupoints in animals. Rev. Sci. Tech. 13(3), 927-933.

Zhao, Z. 2008. Neural mechanism underlying acupuncture analgesia. Prog. Neurobiol. 85(4), 355-375.

Zijlstra, F.J., van den Berg-de Lange, I., Huygen, F.J.P.M. and Klein, J. 2003. Anti-inflammatory actions of acupuncture. Mediators Inflamm. 12(2), $59-69$. 